\title{
La musa casera: poesía de circunstancias y estética bajobarroca en el Ramillete poético de las discretas flores (1706) de José Tafalla Negrete
}

Antonio SÁnchez Jiménez

Université de Neuchâtel

CES.XVIII, núm. 25 (2015), págs. 219-235.

Agradecemos a Elena Cano Turrión sus generosas observaciones. Para un análisis mucho más completo de uno de los textos que examinamos, el «antiprólogo» al Ramillete de Tafalla, véase su trabajo, en este mismo volumen. 


\section{Resumen}

Al estudiar los textos preliminares del Ramillete poético de las discretas flores (1706) de José Tafalla y Negrete comprobamos la ambigua reacción de los editores ante la posición de la poesía en la sociedad del Bajo Barroco. El «discreteo», actitud relajada, tono oral e incluso prosaico de esta poesía fue consecuencia de su nuevo papel en la sociedad, en la que servía para promover la interacción en reuniones informales. El Ramillete representa esas características estéticas del Bajo Barroco (prosaísmo, oralidad, predominio de la circunstancia, tono y temática distendidos), pero los prologuistas las percibieron como un problema, al menos en contraste con una decisión (imprimir los poemas) que alteraba esencialmente la función social de los textos de Tafalla.

\section{Palabras clave}

José Tafalla y Negrete, Ramillete poético de las discretas flores, prosaísmo, función social de la poesía, paratextos, Bajo Barroco

\section{ABSTRAC}

The preliminary texts to José Tafalla y Negrete's Ramillete poético de las discretas flores (1706) show the editors' ambiguous reaction to the position of poetry in Low Baroque society. This poetry's discreteo, its relaxed attitude, and its oral —even prosaic — tone, stemmed from its new social role as facilitator of interaction in informal meetings. Tafalla's Ramillete clearly represents these Low Baroque aesthetics (prosaic and oral tone, importance of the social circumstances surrounding the poem, relaxed tone and themes), but the writers who penned the preliminary texts to the book perceived them as problematic, as they were in contrast to a decision (printing the poems in a book) that essentially altered the social function of Tafalla's poems.

\section{KEYWORDS}

José Tafalla y Negrete, Ramillete poético de las discretas flores, prosaic tone, social function of poetry, paratexts, Low Baroque

Recibido: 30 de enero de 2015. Aceptado: 2 de marzo de 2015. 
Los escasos críticos que a lo largo de la historia han comentado el Ramillete poético de las discretas flores (1706 y 1714) de José Tafalla Negrete (1639c. 1696) ${ }^{1}$ han enfatizado el tenor circunstancial de los poemas de la colección, característica que para la crítica tradicional era claramente negativa. Así, ya Leopoldo Augusto Cueto lamentaba que Tafalla, doctor y abogado de los Reales Consejos de Aragón, fuera «uno de los dechados más cabales, y por consiguiente más lastimosos, de la poesía familiar, y por decirlo así, casera, que sustituyó malamente a aquella poesía de intención segura, de arrobamiento místico, de majestuoso arranque, que había resonado en la lira de los Argensolas, de los Leones y de los Herreras» ${ }^{2}$. El juicio de Cueto resulta interesantísimo porque pone de relieve lo que para este crítico era la diferencia clave entre la estética del Bajo Barroco y la de la primera mitad del siglo: frente a la majestad y altas miras de la literatura altobarroca, Cueto opone el «prosaísmo» bajobarroco. Para el erudito, esta estética explica que a Tafalla «Santa Teresa y santa Isabel» no le inspiren «más que frívolas chambergas», frase con la que Cueto contrapone una materia en principio alta con una estética que considera rastrera. Lo único positivo que Cueto tiene que comentar acerca de ese peculiar estilo de Tafalla es que «suele ser castizo y propio» y que «si rinde culto a la moda de los conceptos, se echa de ver al propio tiempo que es costumbre y alarde, no tendencia natural de su ingenio». Es decir, para Cueto Tafalla fue un poeta talentoso o, por lo menos, correcto, pero que tuvo la mala fortuna de escribir en un periodo de gusto descarriado que Cueto compara insistentemente con un nimio «discreteo» ${ }^{3}$.

Nuestro trabajo examina cómo se relaciona este «discreteo» con la poética del momento, y especialmente cómo se representa y asume en los preliminares del volumen de Tafalla. Para ello, repasamos en primer lugar el estado de la

1 Alain BèGue, «Poetas menores de la segunda mitad del siglo XVII», en Pablo Jauralde Pou, Delia Gavela y P. C. Rojo Alique (eds.), Diccionario filológico de literatura española (siglo XVII). Volumen II, Madrid, Castalia, 2010, pág. 738.

2 Leopoldo Augusto Cueto, marqués de Valmar, «Bosquejo histórico-crítico de la poesía castellana en el siglo XVIII», en Leopoldo Augusto Cueto (ed.), Poetas líricos del siglo XVIII, Biblioteca de Autores Españoles 61, Madrid, Rivadeneyra, 1869, pág. XLIII.

3 Todas las referencias en Cueto, «Bosquejo histórico-crítico», pág. XLIII. 
cuestión sobre este poeta zaragozano y explicamos las singularidades de disposición e historia textual del Ramillete poético. En segundo lugar, analizaremos los preliminares que escribieron para el Ramillete don Pedro Miguel de Samper («Aprobación»), el editor del volumen, Manuel de Román (dedicatoria), y, por último el autor anónimo del prólogo «A quien leyere», texto que refleja una interesante actitud hacia la estética y perfil autorial de Tafalla y hacia su incómoda posición en un momento de transición poética.

A la hora de describir la estética del Bajo Barroco, la crítica ha recurrido al concepto del «prosaísmo», término en un principio peyorativo que usaran Juan Manuel Rozas y Miguel Ángel Pérez Priego ${ }^{4}$ y Russell P. Sebold ${ }^{5}$ para describir el gusto del momento. Sin embargo, el concepto ha sido adoptado recientemente por críticos como Jesús Pérez Magallón ${ }^{6}$ y Alain Bègue 7 y el análisis de Pedro Ruiz Pérez $^{8}$ lo ha elevado a categoría artística merced a una analogía con la estética de la poesía de la experiencia. Como explican estos críticos, el prosaísmo bajobarroco es una nueva retórica de la simplicidad, un rechazo de la «afectación, la oscuridad, la dificultad y la complejidad, promulgando en su lugar la llaneza y la simplicidad» ${ }^{9}$, como ya había señalado Pérez Magallón ${ }^{10}$. El prosaísmo consiste, pues, en un rechazo consciente de la transcendencia altobarroca ${ }^{11}$, en un «soslayo de un verdadero lirismo» ${ }^{12}$ que debemos relacionar con un fenómeno más amplio sobre el que han llamado la atención Aurora Egido ${ }^{13}$, Pérez Magallón ${ }^{14}$,

4 Juan Manuel Rozas y Miguel Ángel Pérez Priego, «Trayectoria de la poesía barroca», en Bruce W. Wardropper (ed.), Historia y crítica de la literatura española. Siglos de Oro: Barroco, Barcelona, Crítica, 1983, pág. 638.

5 Russell P. SEBoLd, «"Mena y Garcilaso, nuestros amos”: Solís y Candamo, líricos neoclásicos», en Jesús Pérez Magallón (ed.), Del Barroco a la Ilustración. Actas del Simposio celebrado en McGill University, Montreal, 2 y 3 de octubre de 1996, Charlottesville, The University of Virginia (Anejos de Dieciocho, 1), 1997, pág. 157.

6 Jesús Pérez Magallón, «Hacia un nuevo discurso poético en tiempos de los novatores», Bulletin Hispanique, 103 (2001), pág. 453.

7 Alain BÈGUe, "Degeneración" y "prosaísmo" de la escritura poética de finales del siglo XVII y principios del XVIII: análisis de dos nociones heredadas», Criticón, 103-104, (2008), pág. 33; Alain BècuE, «Hacia la modernidad: nuevas actitudes del yo lírico en la poesía española entre barroco y neoclasicismo», Cuadernos Aspi, 1 (2013), pág. 65.

8 Pedro Ruiz Pérez, «Entre dos parnasos: poesía, institución y canon», Criticón, 103-104 (2008), pág. 213; Pedro Ruiz Pérez, «Para la historia y la crítica de un periodo oscuro: la poesía del Bajo Barroco», Calíope, 18 (2012), págs. 9-25.

9 BèGue, «Hacia la modernidad», págs. 64-65.

10 Pérez Magallón, «Hacia un nuevo discurso poético», pág. 467.

11 Ruiz Pérez, «Para la historia y la crítica», pág. 21.

12 Ruiz Pérez, «Entre dos parnasos», pág. 213.

13 Aurora EGIDO, «Literatura efímera: oralidad y escritura en los certámenes y academias del Siglo de Oro», Edad de Oro, 7 (1988), págs. 69-87.

14 Pérez Magallón, «Hacia un nuevo discurso poético», pág. 457. 
Ruiz Pérez ${ }^{15}$ y Bègue ${ }^{16}$ : la relación entre poesía y oralidad. Esta vuelta a la oralidad de los poetas bajobarrocos se explica también por el hecho de que «la poesía de las últimas décadas del siglo XVII y de las primeras del siglo XVIII [...] fuera, en gran medida, fruto de la ocasión y circunstancia y diese muestra de una decidida irrupción de la esfera de lo cotidiano» ${ }^{17}$.

Prosaísmo, oralidad, poesía circunstancial: tenemos aquí elementos suficientes para proponer una hipótesis que englobe la totalidad del fenómeno y explique la estética de la poesía bajobarroca. El factor decisivo para formarla habría sido la progresiva aparición de un nuevo modelo de sociabilidad que ha sido descrita por estudios como los de Ruiz Pérez ${ }^{18}$ y Eva Velasco Moreno ${ }^{19}$. Se trata de un nuevo estilo de interacción basado en «grupos pequeños reunidos en numerosas ocasiones en torno a una mujer por el mero placer de la conversación, la lectura en voz alta o el juego» ${ }^{20}$. En ellos «se congregaban personas que buscaban otras formas de integración social, alejadas del rígido medio cortesano, pero también del ámbito de las clases populares», reuniéndose en círculos en origen de «carácter espontáneo y formal», pero que según fue avanzando el siglo XVIII «tendieron a transformarse en instituciones con reglamentos» ${ }^{21}$. Este nuevo modelo de sociabilidad se diferenciaría de la academia áurea precisamente por su informalidad ${ }^{22}$, así como por fomentar un trato mucho más iguali-

15 Ruiz Pérez, «Para la historia y la crítica», pág. 20.

16 Alain Bègue, «Aproximación a la lengua poética de la segunda mitad del siglo XVII: el ejemplo de José Pérez de Montoro», Criticón, 97-98 (2006), págs. 153-170; Alain Bègue, "Oralidad y poesía en la segunda mitad del siglo XVII», en José María Díez Borque (ed.), Cultura oral, visual y escrita en la España de los Siglo de Oro, Madrid, Visor, 2010, págs. 57-98.

17 BÈGue, «Hacia la modernidad», pág. 64.

18 Pedro Ruiz Pérez, «Modelos editoriales y perfiles de autor tras el canon áureo (1650-1700)», en Ignacio García Aguilar (ed.), Tras el canon. La poesía del Barroco tardío, Vigo, Academia del Hispanismo, 2009, pág. 118; Ruız Pérez, «Para la historia y la crítica», pág. 14.

19 Eva Velasco Moreno, «Sociabilidad e instituciones en el tránsito del siglo XVII al XVIII en España», en Mechthild Albert (ed.), Sociabilidad y literatura en el Siglo de Oro, Madrid, Iberoamericana, 2013, págs. 345-364.

20 Una prueba de la importancia de la mujer en estos nuevos espacios de comienzos del xvIII es la polémica en torno al chichisveo (Ángeles Arce Menéndez, «Sobre el cicisbeo y el chichisveo: ¿una misma realidad del siglo XvıI?», Cuadernos para la investigación de la literatura hispánica, 20 (1995), págs. 101-122). Pérez Magallón, «Hacia un nuevo discurso poético», pág. 457, enfatiza el factor de la presencia femenina en estas reuniones. Sobre la poesía escrita por mujeres, véase el trabajo de Nieves Romero-DíAz, «Aproximaciones a la poesía secular escrita por mujeres, 1650-1700. Una propuesta metodológica», Calíope, 18 (2012), págs. 102-126. Sobre la relación entre esta poesía y el galanteo, véase Ruzz Pérez, «Para la historia y la crítica», págs. 21-22.

21 Velasco Moreno, «Sociabilidad e instituciones», págs. 349-351.

22 Andreas GELZ, «Traducir como práctica cultural. Tertulias, academias y traducción en la España del siglo XVIII», Revista de Literatura, 63 (2001), págs. 89-114; Velasco Moreno, «Sociabilidad e instituciones», págs. 353 y 355 . A lo largo del siglo XvII, y según se iban incorporando a la esfera del poder, estas instituciones fueron cobrando cada vez mayor rigidez, y se fueron dotando de estatutos. Velasco Moreno («So- 
tario entre los miembros ${ }^{23}$. A esto se unió, ya en época ilustrada, un claro afán por proyectarse al exterior y perseguir el bien público ${ }^{24}$.

Este nuevo estilo de reunirse y conversar ${ }^{25}$ le concedió un lugar diferente a la poesía. En la nueva sociabilidad bajobarroca que fomentaban estas reuniones más igualitarias e informales, la poesía servía como objeto de intercambio y entretenimiento íntimo, informal y elegante. En consecuencia, los poetas de esa generación abandonaron progresivamente el tono transcendente que adoptaba mucha poesía altobarroca y asumieron, más bien, una actitud relajada que no se distinguiera demasiado del ámbito oral de los salones en que se empleaban sus textos. Este ambiente de reunión de salón informal ${ }^{26}$, tan diferente de la academia altobarroca, influyó notablemente en la poesía del momento, aunque no es el único espacio que propició el tono de familiaridad comentado, pues también tenemos numerosos poemas que servirían como glosa epistolar a regalos a los que acompañaban. En todo caso, según esta nueva función social del texto que aparece en el Bajo Barroco el poeta deja de ser un desengañado despertador de conciencias, un descubridor de nuevos modos de conocer la realidad o un teatro de pasiones $^{27}$, y se convierte en un facilitador de la interacción social o en un

ciabilidad e instituciones», pág. 357) resume el proceso, que dependía de varios factores: «uno, la capacidad de presentar un proyecto que revirtiera en beneficio del interés público y colectivo; dos, la aceptación de unas normas de funcionamiento interno de las academias que de alguna forma daban más rigidez a la sociabilidad pero, a cambio, garantizaban la continuidad institucional; y tres, el alejamiento de los cenáculos de la política y de las querellas intelectuales».

23 Andreas GeLz, «Sociabilidad y literatura entre el Siglo de Oro y el Siglo de las Luces: género literario e hibridación cultural», en Mechthild Albert (ed.), Sociabilidad y literatura en el Siglo de Oro, Madrid, Iberoamericana, 2013, pág. 365.

24 María José Rodríguez SÁnchez de León, «La institución académica en el siglo XVIII: sociabilidad y quehacer literario», Cuadernos de Ilustración y Romanticismo, 8 (2000), pág. 4; Giovanni STIFfoni, «Los "novatores" y la "crisis de la conciencia europea”", en Ramón Menéndez Pidal y José María Jover Zamora (eds.), Historia de España Ramón Menéndez Pidal. La época de los primeros Borbones. La cultura española entre el Barroco y la Ilustración (1680-1759), Madrid, Espasa-Calpe, 1985, vol. 29/2, pág. 24.

25 Joaquín Álvarez Barrientos, «Reunirse y conversar: las tertulias del siglo XVIII», Ínsula, 738 (2008), págs. 7-8.

26 Ruiz Pérez habla de poesía para «salones y gabinetes» y de «salón mundano» (Ruzz Pérez, «Para la historia y la crítica», págs. 20 y 21 ).

27 Pérez Magallón («Hacia un nuevo discurso poético», pág. 458) ha resaltado cómo en las academias de la época los poetas «abandonan completamente la intimidad confesional de la primera persona y escriben en su lugar versos casi totalmente impersonales en tercera persona. [...] Así, la academia se desvió del paradigma petrarquista en tres aspectos relacionados: la proyección de sinceridad y credibilidad; el tipo de relación textual entre el poeta y su auditorio; y la separación de las dos facetas gemelas del poeta y amante tan cuidadosamente unidas en la poesía petrarquista». Particularmente interesante resulta el uso que hace de un término de Paul Julian Sмгтн («The Rhetoric of Presence in Poets and Critics of Golden Age Lyric: Garcilaso, Herrera, Góngora», Modern Language Notes, 100, (1989), págs. 223-246) para subrayar que «lo que se destruye en esa lírica es la "rhetoric of presence" " propia de la poesía de la primera mitad del siglo XVII. 
cronista de la misma ${ }^{28}$. Por consiguiente, su poesía toma un tono cercano y se tiñe de prosaísmo, es decir, de oralidad, porque esa literatura es parte esencial de la sociabilidad, del «discreteo» que tanto molestaba a Cueto ${ }^{29}$.

Pocos poetas del momento ejemplifican mejor esta poesía de «discreteo» que Tafalla. De su obra conservamos la antología póstuma que nos ocupa ( $R a-$ millete poético), que publicó en 1706 y 1714 su amigo Manuel Román con material que había ido recopilando don Manuel de Contamina ${ }^{30}$. El volumen fue compuesto por un grupo aragonés que formaban Román, Contamina y el cronista real de Aragón, Pedro Miguel de Samper, amén de «Nycio Pyrgeo, académico peregrino en la Academia de los Misterios» ${ }^{31}$, de los cuales sabemos que al menos Román, Samper y Tafalla coincidieron en la Academia del príncipe de Esquilache ${ }^{32}$. En principio, el libro de Tafalla sigue una disposición muy habitual ${ }^{33}$, comenzando con «poesías humanas» y acabando con las «sagradas». Sin embargo, tras ellas encontramos unas paráfrasis de los salmos ${ }^{34}$ que no son obra suya, y que según el editor «se ha puesto aquí para llenar el pliego» (pág. 301), y, además, otra serie de poemas sacros y profanos de Tafalla:

Concluida ya la impresión de este libro, se hallaron las poesías siguientes y se ponen aquí como adición, porque darán tanto crédito a su autor como todas las demás; esta es desgracia de las obras póstumas, que siendo partos del entendimiento,

28 Una consecuencia de este cambio de papel de la poesía, que había abandonado su «pretensión —falaz, lo sabemos— de autenticidad emocional», es el afán por «llamar la atención sobre su propia textualidad, su naturaleza como productos del ingenio, sobre la maestría técnica y temática del poeta más que sobre la expresión de unos sentimientos» (PÉrez MAGallón, «Hacia un nuevo discurso poético», pág. 459).

29 Cueto, «Bosquejo histórico-crítico», pág. XLIII.

30 Contamina y Ortal era jurado de la ciudad de Zaragoza y un notable mecenas en la dicha ciudad. Por ejemplo, organizó las fiestas por la llegada a España de la nueva esposa de Carlos II, Mariana de Neuburg, publicadas en 1690. Contamina se inclinó de parte de Felipe V en la Guerra de Sucesión, apuesta que debió de aumentar notablemente su capital simbólico y financiero.

31 Willard F. KING (Prosa novelística y academias literarias en el siglo XVII, Madrid, Real Academia Española, 1963) no da noticia de esta academia ni entre las madrileñas ni entre las aragonesas. Para estas últimas, véase el trabajo de Aurora Egido (Aurora EGIDo, «Las academias literarias de Zaragoza en el siglo XVII», en Aurora Egido (ed.), La literatura en Aragón, Zaragoza, Caja de Ahorros, 1984, págs. 101-128).

32 José Sánchez, Academias literarias del Siglo de Oro español, Madrid, Gredos, 1961, págs. 267-268. EGIDO, «Las academias literarias de Zaragoza», págs. 120-127.

33 Sobre los modelos editoriales de la segunda mitad del siglo XVII, véase el trabajo de Ignacio GARCíA Aguilar, «Tras el Parnaso (1648): aproximación a modelos editoriales de mediados del XVII», en Ignacio García Aguilar (ed.), Tras el canon. La poesía del Barroco tardío, Vigo, Academia del Hispanismo, 2009, págs. 61-76.

34 José Tafalla Negrete, Ramillete poético de las discretas flores del amenísimo, delicado numen del dotor don José Tafalla Negrete, Zaragoza, Manuel Román, 1706, págs. 295-301. Todas las referencias remiten a esta edición. 
no puede darles la protección, la viveza y orden que les daría su mismo autor, que es el padre natural (pág. 303).

A su vez, dentro de cada sección la ordenación es prácticamente inexistente, o por lo menos muy laxa. En la primera encontramos loas, abundantes romances, muchísima poesía de circunstancias, pero también sonetos cultos (pág. 46), algunos burlescos (pág. 62), canciones (pág. 83) e incluso una pequeña epopeya burlesca en tres cantos, la «Historia de los muchísimos desdenes de la bella ingrata» (págs. 111-115). Pero sin duda lo más abundante es la mencionada poesía de circunstancias o «versificación de la vida pública» ${ }^{35}$, de la que citaremos algunos ejemplos: «Habiendo estado en conversación con unas damas embozadas que iban en un coche, le mandó una de ellas describiese en una décima lo que le había parecido de su prosa y si las había conocido glosando este verso: "La ventanilla del coche” ( pág. 97), «A una dama, en ocasión de haber parido un hijo teniendo ya otros tres» $\mathrm{y}$ «A la elección de ministra de Altabas hecha en la persona de la señora doña Margarita Bayetola» (pág. 102). Asimismo, tenemos decenas de poemas de circunstancias que siguen el esquema del «Dieron al autor estos versos para glosarlos» (pág. 107), o del «Responde a un papel por los mismos asonantes en que se escribió» (pág. 108), que nos muestran cómo la poesía de Tafalla formaba parte de un tipo de sociabilidad epistolar paralela a la sociabilidad in praesentia de los salones. De ella también dan fe los poemas que acompañaban regalos, muy en la línea del célebre de Eugenio Gerardo Lobo, su «Acompañó a un regalo de perniles y chorizos para el excelentísimo señor conde de Aguilar (quien fue muy dado a la filosofía moderna)» (pág. 141). Nos referimos a textos como «Remite un puerquecito de leche» (pág. 144), «Remite una señora guantes a un caballero porque le hacían daño los de ámbar que él traía» (pág. 145) o «Remite a una señora unos guantes de Roma por una ensalada que le envió» ${ }^{36}$. En cuanto a la poesía religiosa, también está dominada por las composiciones de circunstancia. Parece remitir a ella el extenso santoral en romances, por no hablar de los poemas a monjas en ocasión de tomar el velo (págs. 289-295), o de textos como «En ocasión de haber sacado a nuestra señora de Atocha por necesidad de agua, dejándola en el convento de la Trinidad, se pidió al autor hiciese una copla a este asunto, aludiendo al misterio de la Concepción en cuatro especies de bebidas, y dijo:»

35 Ruiz PÉrEz, «Modelos editoriales», pág. 122.

36 De otro orden parecen «A una dama que le pidió al autor una merienda» (págs. 118-119) o «A una dama que le pidió unos gazapos» (págs. 174-175), que más que ser testimonios de intercambios reales ilustran situaciones tópicas, por lo que servirían para amenizar alguna reunión. 


$$
\begin{aligned}
& \text { Copla } \\
& \text { En la Trinidad se aloja, } \\
& \text { sin tener de limo-nada, } \\
& \text { esta que del Cielo vino } \\
& \text { solo para darnos agua (pág. 206). }
\end{aligned}
$$

Los editores intervienen en este maremágnum en diversas ocasiones, aclarando referencias o incluso alegorizando sobre la España de Felipe V, que como sabemos no llegó a conocer Tafalla: «Esta glosa escribió el autor muchos años ha, y puedo aplicarse a la feliz y estrecha unión de las dos coronas de España y Francia en las ocurrencias presentes en que nuestro católico monarca Filipe $\mathrm{V}$ puede esperar vencer sus enemigos unido a su invencible abuelo, el gran rey de Francia Luis XIV» (pág. 192). En suma, el Ramillete poético es sobre todo un compendio de textos de circunstancias que ponen de relieve la estética de la «poesía sociable», oral y prosaica a la que nos referimos arriba.

Aunque no existe demasiado volumen crítico sobre Tafalla ${ }^{37}$, los estudiosos que se han ocupado del Ramillete han reconocido en el libro este dominio de la poesía de circunstancias. Ya hemos visto que Cueto ${ }^{38}$ lo relacionó con lo que llamaba «discreteo», conexión que, privada del sentido peyorativo que el concepto tenía para Cueto, adoptan también los críticos modernos. Así, Pérez Magallón ${ }^{39}$ subraya que la poesía del Ramillete «aparece marcada ciertamente por su carácter académico, es decir, por haber sido concebida casi toda ella para las academias literarias o en su contexto institucional», afirmación que nos parece totalmente acertada siempre y cuando se especifique en qué se diferenciaban esas academias de las altobarrocas. Por otra parte, también Bègue pone de relieve esta relación de las composiciones de Tafalla con «la realidad socioliteraria del autor»:

Los títulos de las composiciones poéticas hablan por sí mismos para comprender el alcance de su impronta. Y no son pocos los ejemplos de las obras poéticas compuestas en circunstancias precisas [...] con una función y una finalidad claramente epistolar. Fruto de las relaciones mundanas y amistosas, los poemasepístolas, de formas y metros diversos, adoptan unos rasgos estilísticos muy particulares (Bègue 2004: I, 3, 724-6; 2010: 3, 778-80) en los que predominan la autorreferencialidad — con alusiones a la realidad socioliteraria del autor, a la práctica

37 No hemos podido consultar la tesis inédita de María Rosario Juste SÁNCHEz (Edición y estudio de la obra de José Tafalla y Negrete, Zaragoza, Universidad de Zaragoza, 1991).

38 Cueto, «Bosquejo histórico-crítico», pág. XuIII.

39 Pérez Magallón, «Hacia un nuevo discurso poético», pág. 462. 
de la escritura poética, a su progresiva profesionalización, etc.—, la oralidad del discurso, la adopción de un tomo familiar, prosaico y jocoserio [...], así como una clara identificación del yo lírico con el escritor ${ }^{40}$.

Además, tanto Pérez Magallón ${ }^{41}$ como, en su estela, Bègue ${ }^{42}$, han analizado textos del Ramillete para ejemplificar con ellos el cambio de actitud de estas composiciones de Tafalla con respecto a la poesía altobarroca: concretamente, el poema elegido ha sido el madrigal «A un reloj de madera» (pág. 90), que en vez de evocar el tema del desengaño celebra la transformación de la madera en una entidad superior, un ingenio mecánico. En suma, comprobamos que el Ramillete ha servido para ilustrar tanto la nueva mentalidad bajobarroca como la elevada influencia de la circunstancia social en la poesía del momento. Es un aspecto que Pérez Magallón ${ }^{43}$ relacionara con las academias de la época y que nosotros conectamos de modo más amplio con un nuevo tipo de sociabilidad y de academia. En todo caso, está claro que el Ramillete de Tafalla evidencia la impronta de un modo diferente de relacionarse que le otorgó un papel a la poesía muy diverso del que esta adoptaba durante la primera mitad del siglo.

Ahora bien, si en el siglo XIX Cueto se sintió incómodo ante el «discreteo» de Tafalla, es lícito preguntarse cómo lo representaron, explicaron o justificaron en el momento los prologuistas del Ramillete ${ }^{44}$, pues estos literatos se vieron ante la paradoja de imprimir para un gran público anónimo textos que Tafalla había producido para unas circunstancias muy concretas y para relaciones sociales determinadas, marcadas por la informalidad y la oralidad. Es decir, al recopilar e imprimir los textos del Ramillete, la función social de las poesías de Tafalla cambiaba y situaba a los prologuistas en una situación contradictoria que debían explicar ${ }^{45}$ : mediante el simple acto de impresión, lo efímero pasaba a la posteridad, lo privado, a manos de un público anónimo. En las páginas que siguen vamos a examinar su actitud hacia esta paradoja centrándonos en tres paratextos ${ }^{46}$ : en primer lugar, la dedicatoria «Al magnífico y muy ilustre

40 BèGue, «Hacia la modernidad», pág. 81.

41 Pérez Magallón, «Hacia un nuevo discurso poético», pág. 464.

42 BèGue, «Hacia la modernidad», pág. 69.

43 Pérez Magallón, «Hacia un nuevo discurso poético».

44 Para un estudio genetteiano acerca de la función de esta materia prologal, véase Pérez Magallón (Jesús Pérez Magallón, «Los umbrales del Ramillete poético, de Tafalla y Negrete», Criticón, 119 (2013), págs. 23-34).

45 Recordemos, con Andreas Gelz (GELz, «Sociabilidad y literatura», pág. 370), que «la publicación de lo que ha sucedido en una academia literaria la convierte de una reunión efímera, comentando y festejando un acontecimiento al que está subordinada (fiesta religiosa, familiar, acontecimiento histórico), en un texto literario que obedece a otra lógica, propia de la comunicación escrita y literaria».

46 Todos ellos carecen de paginación. 
señor don Manuel de Contamina», del editor del volumen, Manuel Román; en segundo lugar, la «Aprobación» de Pedro Miguel de Samper y, en tercer lugar, el prólogo «A quien leyere», anónimo ${ }^{47}$.

Comencemos por la dedicatoria a Contamina, que es esencial porque nos proporciona mucha información sobre la génesis y función del libro. En ella, Román explica que los textos que componen el volumen fueron recopilados por el aristócrata al que ahora se dirige, que protegió en vida a Tafalla:

[...] fue la casa de vuestra merced el mayor abrigo del autor; la finísima amistad, el más dulce patrocinio; y la generosidad de vuestra merced, su más favorable amparo. No se limitaban estas honras en la persona solamente, sino que pasaban hasta los escritos, hallando estos, como hijos y partos del divino ingenio de aquel favorecido alumno, en el patrocinio de vuestra merced su noble refugio y asilo más seguro.

Román explica en detalle el proceso en las líneas siguientes:

Estos afectos de cordial amigo y la plausible inclinación a lo discreto y ingenioso, que por naturaleza debe resplandecer en vuestra merced, hizo que recogiese y guardase algunas poesías del autor, que ojalá hubieran sido todas, para que con estas que preservó del olvido el cuidado de vuestra merced hubieran salido en este libro a la luz y a la admiración. Por estos respetos, dije que con el cargo de la obligación para el sacrificio se le defraudaba la libertad al obsequio, porque no podía buscarles otro mejor mecenas que las amparase como impresas que al mismo que las había guardado manuscritas.

El patronazgo de Contamina en vida del autor le califica para proteger a estos «hijos»y «partos» de Tafalla, como explica Román con una metáfora lopesca. Sin embargo, este fenómeno provoca una serie de interrogantes estéticos que sería tal vez indecoroso tratar en el género de una dedicatoria, pero que el autor anónimo va a dirimir en su prólogo «A quien leyere». En primer lugar, el comportamiento de Contamina nos enfrenta al problema del coleccionismo: el noble debió de guardar o incluso recopilar los textos de Tafalla, pues aunque muchos poemas pudieron leerse en alguna reunión o academia, ya en casa de Contamina, ya en un salón ajeno, otros debieron de ser enviados a otros personajes mencionados en las composiciones. En este caso, tenemos que imaginar que

47 Dejamos fuera de nuestro estudio otro paratexto, la «Aprobación» de Nycio Pyrgeo, que aunque serviría para ilustrar el contexto académico del Ramillete, no trata la contradicción que nos interesa. 
o bien Contamina le pedía traslados a Tafalla de los poemas que le iba oyendo o bien le solicitaba a otros personajes del círculo social en que se movían esas copias de textos del ingenio. De todos modos, la situación es curiosa, porque al recopilar esos poemas Contamina los saca del contexto en que se emitieron y les priva su razón de ser, otorgándoles una diferente: los poemas ya no son actos de una determinada circunstancia social, sino una entidad nueva. En segundo lugar, aunque muy relacionado con el anterior, tenemos un hecho paralelo: al publicarlos, los poemas —orales y escritos— que funcionaban en la intimidad de un círculo social determinado, glosando o acompañando situaciones efímeras, adquieren una función social diferente ${ }^{48}$. Podríamos interpretar que ahora los poemas monumentalizan y otorgan trascendencia a las situaciones que les daban sentido, pero también que mediante el libro impreso el círculo social gana otro espacio, el impreso: el Ramillete les serviría a los cenáculos zaragozanos para reivindicarse ante los círculos madrileños mencionados ${ }^{49}$, pero también para acompañar nuevas reuniones y servir como objeto alrededor del cual girarían las conversaciones.

En cuanto a la «Aprobación» de Samper, aprovecha perfectamente el contexto genérico de la aprobación, mucho más propicio a las reflexiones metaliterarias que el de la dedicatoria. Concretamente, Samper expresa su preocupación acerca de uno de los problemas que reseñamos arriba: el contraste entre las funciones del poema circunstancial y su versión impresa. Samper la proclama con un lenguaje muy propio de la época, refiriéndose al bien común, cuya consecución, como hemos explicado, era uno de los afanes de las academias ilustradas, y que aparecía como preocupación a lo largo del siglo. En efecto, ya en este texto de 1706 tenemos indicios de que los literatos sentían la presión de dedicarse a saberes útiles, y de que en este ambiente la poesía comenzaba a ser acosada. Por supuesto, el fenómeno no alcanzará su plenitud hasta la célebre epístola poética de Jovellanos a sus amigos salmantinos, pero se encuentra apuntado en esta «Aprobación» de Samper en forma de una defensa de la poesía. Según el cronista real de Aragón, el mundo condena la poesía como un saber inútil, «juzgando que su luz es la Venus del alma, a cuyo esplendor se queman los ingenios inútilmente las cejas, como al fuego material sus alas las mariposas, enajenando las potencias que pudieran servir en beneficio de las repúblicas». Esta censura alcanza con especial a la poesía castellana, pues Samper nota que la latina se emplea «para adorno de declamaciones jurídicas, y aun evangélicas, y apenas hay empeño público de los de mayor seriedad a que no salga, contribuyendo con

48 Ruiz Pérez, «Modelos editoriales», pág. 116.

49 PÉrez Magallón, «Los umbrales», págs. 33-34. 
sentencias, con reflexiones y con moralidades». Sin embargo, la castellana no disfruta de este prestigio y no tiene la misma presencia como vehículo de erudición. Más bien, y aquí viene lo que nos interesa, la poesía castellana frecuenta unos espacios sociales diferentes: «no tiene voz sino en privadas conversaciones, viviendo como hija bastarda retirada entre la familia». Es decir, Samper reconoce que la poesía de su época desempeña un papel circunstancial en las reuniones sociales informales a las que nos hemos referido arriba, y que toma de ellas un carácter oral que queda en evidencia y fuera de contexto al imprimirse los textos. Por supuesto, el Ramillete de Tafalla ejemplifica perfectamente esa poesía que vive «como hija bastarda retirada entre la familia», esa poesía que se veía ya presionada por las exigencias de utilidad común propias del siglo y que Samper se veía obligado a defender.

Sin embargo, para hacerlo el cronista real no se mantiene fiel a las características de los textos de Tafalla, y elige más bien apoyarse en una defensa tópica de una literatura que, sostiene, tiene a la vez deleite, utilidad y decencia ${ }^{50}$. Para ello Samper compara los textos de Tafalla con los de otros poetas áureos, no encontrándolos

[...] inferiores a los énfasis heroicos de Góngora, a las dulces suavidades de Lope, a las provechosas moralidades de los Leonardos, a la propriedad de las frases de Ulloa, a los profundos conceptos de Solís, a las saladas discreciones de Montoro, ni a los vivos picantes de Quevedo, brilla con una especial gracia que no se encuentra en los otros.

Es decir, Samper niega que la poesía de Tafalla sea inútil, y reclama para ella un conjunto de virtudes que ejemplifica con una especie de canon de poetas alto y bajobarrocos. Es una mezcla que revela que para Samper no ha habido un cambio de estética entre la primera mitad del siglo y sus propios días, y que por tanto nos interesa menos que aquellos momentos en los que el cronista real enfatiza la especificidad de Tafalla. Uno de estos instantes se encuentra hacia el final de la «Aprobación», cuando Samper explica cuál era la actitud de Tafalla hacia sus versos:

Una de las calidades de los poetas debe ser no hacer estimación de sus obras, y por eso don Antonio Solís, no negando que hacía versos, dijo «Pero no hago de ellos caso, que es la disculpa de hacerlos», y don José Tafalla fue tan en extremo despreciador de los que hacía que no solamente no aspiraba a la perpetuidad de

50 Pérez Magallón, «Los umbrales», pág. 30. 
su nombre con el beneficio de la prensa, pero ni le merecieron sus poesías la ligera solicitud de guardarlas, porque daba hasta los borradores, pues de muchas puedo ser testigo, y esa excelencia de su grandeza de ánimo ha sido perjudicial ahora a los que deseamos el aplauso de su entendimiento peregrino.

En esta ocasión sí que encontramos una particularidad bajobarroca: la falta de trascendencia no solamente del contenido de los poemas, sino de la autoconcepción del poeta y de la idea de la poesía. Se diría que, tras el paréntesis altobarroco, la idea de la poesía regresa a la sprezzatura renacentista, probablemente impulsada por una función social semejante, pues al cortesano renacentista le correspondería ahora el académico o poeta de salón bajobarroco. En todo caso, vamos a comprobar que la falta de «solicitud» acerca de su poesía que percibe Samper en Tafalla creaba un problema que sobrepasaba con creces el de la falta de borradores.

Se trata de una cuestión estética que preocupaba al autor anónimo del extraordinario prólogo «A quien leyere», dedicado a ventilar dudas acerca de la naturaleza de la nueva poesía del momento y de las paradojas que provocaba editarla. Son problemas centrales en un prólogo que quiere explicar, ante todo, por qué Román y compañía han decidido publicar las poesías de Tafalla, y que quiere contestar objeciones que los editores intuyeron (o tal vez llegaron a recibir) a la hora de imprimir el Ramillete.

Efectivamente, el prólogo comienza presentando el supuesto sentir de unos presuntos detractores de la obra: «Opiniones hubo, y de fundamentos no vulgares, que persuadían deberse retirar estas poesías y no sacarlas al teatro de los discretos por hacer merced a su autor». Se trata de una objeción basada en argumentos estéticos, pues estos críticos pensaban que Tafalla gozaba de una fama tal que los textos que se reunieran para publicar deberían por lo menos igualarla:

La razón principal era porque el numen felicísimo del doctor don José Tafalla se mereció unos aplausos tan universales que en el concepto de todos ninguno de los más cándidos cisnes que han llenado de dulzuras a los amenos márgenes del Ebro le podía pleitear los laureles. Para acreditar este elogio era preciso presentar al mundo unas obras tan grandes y sublimes que suspendiesen hasta los ecos de su misma fama.

El prologuista responde explicando cuáles fueron las dificultades que encontraron los editores, y volviendo a resumir el proceso mediante el que consiguieron los textos. Al explicar que estos poemas eran borradores, el anónimo en- 
tra ya en cuestiones estéticas. El escritor recuerda que los poemas del Ramillete no habían sido corregidos por Tafalla y que, y esto es lo que más nos interesa, eran poesía de circunstancias totalmente supeditada a estas, y por consiguiente sometida a exigencias de tiempo:

Para todo habría en la multitud de los elegantes y conceptuosos versos que compuso, pero no se han tenido a la mano para imprimirlos sino estos precisamente que observó la amistad y la afición del magnífico don Manuel de Contamina. Y aun estas limitadas poesías no estaban con la última mano y lima reflectiva de su autor, sino escritas en papeles inútiles, en cubiertas de cartas y tan en borradores que se conocía haber escrito las más de ellas no para que el ingenio se luciese con la armonía de las voces, con el número sonoro de las sílabas ni con la delicada novedad de los conceptos, sino para cumplir cuanto antes con aquellos que lo empeñaban más a escribirlas que a componerlas.

En la última frase del pasaje citado el prologuista contrapone dos modos de escribir poesía: el estetizante y el social. Con el primero el poeta persigue el goce estético, ejercitando y dando a conocer su ingenio con lo poético de los términos, lo armonioso del ritmo y lo sorprendente, pero elegante, de los conceptos. Estos objetivos estéticos e intelectuales de lo que el prologuista anónimo llama «componer» se oponen al segundo modo de hacer poesía, el «escribir», en el que todo lo anterior se inclina ante las exigencias sociales de los receptores que van a consumir el poema. Se trata de una contraposición que el autor del prólogo desarrolla en las frases siguientes:

Este modo de escribir mandado es muy violento, aun para el numen más obediente, y son muy pocos los que entienden las diferencias que se notan en los poemas que nacen de impulso proprio, y en los que son puramente compuestos por obediencia. Casi todas las poesías de este Ramillete, o bien épicas o bien líricas, ya en asuntos amorosos, ya heroicos o ya sacros, se conoce que eran para ajenos desempeños y tiempos precisos, donde quitando la libertad al furor poético lo reducían a escribir, aunque nunca estuviese inspirado. Este es un modo de escribir sin espíritu y sin fervor donde obra como esclava la dulzura y como atareada la facilidad. Así compuso los versos que ahora salen a la luz un poeta que por ninguna de estas poesías se pudo merecer el renombre de «divino aragonés» en la corte de España.

El editor explica aquí su idea acerca de la poesía de circunstancias, «modo de escribir mandado» y «violento» que contrapone con el verdadero, el compuesto por «impulso proprio». Aquí el prologuista introduce un nuevo concepto, 
pues explica que estos poemas de circunstancias se alejan del verdadero arte no solo porque se someten a exigencias temporales que impiden pulir los textos, sino también porque obligan al poeta a escribir sin «furor poético», «espíritu», «fervor» e inspiración. Son todos términos que aluden al aspecto irracional de la creación poética y que se solían usar desde la Antigüedad para defender la poesía y proclamar su autonomía. Es una característica que el prologuista añora en la época bajobarroca en que le tocó vivir, época en la que predomina más bien un poeta de salón como el que edita en el Ramillete, dominado por unas circunstancias que el editor pinta con un lenguaje muy fuerte y en gran parte destilado de los campos semánticos de la sumisión y la esclavitud («mandado», «violento», «obediente», «obediencia», «quitando la libertad», «reducían», «esclava»).

En suma, los textos preliminares del Ramillete de Tafalla muestran la ambigua reacción que los editores del volumen experimentaron ante la novedosa posición que ocupaba la poesía en la sociedad del Bajo Barroco. Hemos observado que esta poesía se caracterizó por un tono de «discreteo», es decir, por una actitud relajada, por tonos orales e incluso prosaicos y por temas circunstanciales y en toco caso poco trascendentes. Asimismo, hemos propuesto que estas características surgieron como consecuencia del nuevo papel de la poesía en la sociedad del momento, en la que servía para promover la interacción en reuniones informales en las que las damas desempeñaban un papel importante y que eran una derivación relajada de las academias poéticas altobarrocas. Es decir, la poesía del Bajo Barroco solo tenía sentido en el contexto de la nueva sociabilidad propia del momento. Además, hemos visto cómo el Ramillete de Tafalla representa perfectamente esas características estéticas (prosaísmo, oralidad, predominio de la circunstancia, tono y temática distendidos) del Bajo Barroco. Ahora bien, también hemos comprobado que los autores de los preliminares del volumen sintieron este tenor como un problema, al menos en contraste con una decisión (recoger, coleccionar y luego imprimir los poemas) que alteraba esencialmente la función social de los textos de Tafalla. Impresa, la poesía de circunstancias perdía su esencia de facilitar la sociabilidad en un tiempo y lugar concretos, y se convertía en un objeto cultural muy diferente, teóricamente destinado a un público amplio y anónimo, y a la eternidad. Esta contradicción entre circunstancia e impresión provocó notables respuestas en los prologuistas del Ramillete. Hemos visto que Samper optó por llevar a cabo una defensa de la poesía castellana y por denunciar que estaba circunscrita a términos familiares (esto es, circunstanciales y poco trascendentes), pero que realmente tenía el potencial de servir al bien común, como según él le mostrarían al lector los poemas del volumen. Por su parte, el autor del prólogo anónimo adoptó una actitud 
contraria, y si cabe más interesante: más que defender los poemas de Tafalla con términos obviamente ajenos y lejanos a los textos, decidió atacarlos. El prologuista denunció una característica de la época que veía ejemplificada en los poemas del libro: la falta de amplias miras estéticas, la falta de autonomía, la sumisión a las exigencias de la sociabilidad bajobarroca. Es curioso que un autor tan cercano a Román, que por otra parte había editado y prologado ya otra colección de poemas de circunstancias ${ }^{51}$, se rebele ante la estética de su tiempo y parezca añorar la de la primera mitad del siglo, más que la alta función de la poesía que proclamaba Jovellanos en 1776. En cualquier caso, la contradicción que provocó el volumen no se llegó a resolver en los preliminares. Más que para proponer una solución al problema, estos paratextos sirven para dar testimonio del mismo, es decir, de cómo sentían algunos eruditos la nueva función social de la poesía en la época.

51 Vicente Sánchez, Lira poética, Zaragoza, Manuel Román, 1688. 